\title{
Fast detection of extrasynaptic GABA with a whole-cell sniffer
}

\author{
Rasmus K. Christensen ${ }^{1}$, Anders V. Petersen ${ }^{1}$, Nicole Schmitt ${ }^{2}$ and Jean-François Perrier ${ }^{1}$ * \\ 'Department of Neuroscience and Pharmacology, Faculty of Health and Medical Sciences, University of Copenhagen, Copenhagen, Denmark \\ 2 Department of Biomedical Sciences, Faculty of Health and Medical Sciences, University of Copenhagen, Copenhagen, Denmark
}

\section{Edited by:}

Stephen R. Williams, University of

Queensland, Australia

\section{Reviewed by:}

C. J. Heckman, Northwestern University, USA

Yehezkel Ben-Ari, Institut National de la Santé et de la Recherche Médicale, France

\section{*Correspondence:}

Jean-François Perrier, Department of Neuroscience and Pharmacology, Faculty of Health and Medical

Sciences, University of Copenhagen, Blegdamsvej 3, DK 2200

Copenhagen, Denmark

e-mail:perrier@sund.ku.dk
Gamma-amino-butyric acid (GABA) is the main inhibitory transmitter of the brain. It operates by binding to specific receptors located both inside and outside synapses. The extrasynaptic receptors are activated by spillover from GABAergic synapses and by ambient GABA in the extracellular space. Ambient GABA is essential for adjusting the excitability of neurons. However, due to the lack of suitable methods, little is known about its dynamics. Here we describe a new technique that allows detection of GABA transients and measurement of the steady state GABA concentration with high spatial and temporal resolution. We used a human embryonic kidney (HEK) cell line that stably expresses $G_{A B} A_{A}$ receptors composed of $\alpha 1, \beta 2$, and $\gamma 2$ subunits. We recorded from such a HEK cell with the whole-cell patch-clamp technique. The presence of GABA near the HEK cell generated a measurable electric current whose magnitude increased with concentration. A fraction of the current did not inactivate during prolonged exposition to GABA. This technique, which we refer to as a "sniffer" allows the measurement of ambient GABA concentration inside nervous tissue with a resolution of few tens of nanomolars. In addition, the sniffer detects variations in the extrasynaptic GABA concentration with millisecond time resolution. Pilot experiments demonstrate that the sniffer is able to report spillover of GABA induced by synaptic activation in real time. This is the first report on a GABA sensor that combines the ability to detect fast transients and to measure steady concentrations.

Keywords: GABA, ambient, spillover, extrasynaptic, inhibition

\section{INTRODUCTION}

$\gamma$-Aminobutyric acid (GABA) is the main inhibitory neurotransmitter in the central nervous system. Its importance is illustrated by the severity of pathologies such as epilepsy, seizures, schizophrenia, or anxiety, which all have been linked to abnormal GABA functions (Ling et al., 1998; Feucht et al., 1999; Benes and Berretta, 2001; Wallace et al., 2001). GABA is synthesized by inhibitory interneurons throughout the central nervous system. Once released, GABA diffuses in the synaptic cleft and activates ionotropic and metabotropic receptors. GABA exerts its direct inhibitory effect by the hyperpolarization and the shunt mediated by ionotropic ligand gated $\mathrm{Cl}^{-}$channels (Chance et al., 2002; Wong etal., 2003). GABA receptors are expressed subsynaptically and extrasynaptically in post-synaptic neurons (Ingham and McAlpine, 2005). The extrasynaptic receptors have particularly high affinity for GABA (Farrant and Nusser, 2005). They are activated by transient GABA overflow from the GABAegic synapses (Farrant and Nusser, 2005). In addition, extrasynaptic receptors are activated by ambient GABA continuously present in the extracellular space (Scanziani, 2000; Farrant and Nusser, 2005; Alle and Geiger, 2007; Bright et al., 2011). Extrasynaptic GABA receptors adjust the excitability of neurons (Otis et al., 1991; Salin and Prince, 1996; Bautista et al., 2010) and regulate the behavior of neuronal networks (Hamann et al., 2002). However, the dynamics of their activation remains unknown. Different studies of the estimates of the ambient GABA concentration in the brain range from ten nanomolars to a few micromolars (Juhasz et al., 1997; Maex and De Schutter, 1998; Huang et al., 2008; Numata et al., 2012). Indeed, the level of extrasynaptic GABA changes with functional state (Lerma et al., 1986; Rowley et al., 1995; Kennedy et al., 2002).

Measuring the variations in ambient GABA concentration is therefore essential for understanding the dynamics of signaling in the brain. So far microdialysis combined with high performance liquid chromatography has been used to measure GABA levels in nervous tissue (Lerma et al., 1986; Kennedy et al., 2002; de Groote and Linthorst, 2007; Vanini et al., 2011). This provides a static picture with time resolution of several minutes, far slower than the time scale of information processing in the brain. Another approach for detecting GABA consists in making an excised outside-out patch from a cell from the central nervous system with the assumption that it contains several $\mathrm{GABA}_{\mathrm{A}}$ receptors (Isaacson et al., 1993). The isolation of $\mathrm{GABA}_{\mathrm{A}}$ receptors requires pharmacological manipulations such as blocking GABA transporters and receptors for other neurotransmitters (Isaacson et al., 1993; Banks and Pearce, 2000; Liu et al., 2005). This technique allows the detection of GABA transients in the extracellular space. However, it is not suitable for measuring ambient GABA because the concentration depends on neuronal activity (Kekesi et al., 1997; de Groote and Linthorst, 2007; Vanini et al., 2011), which is obviously affected by blockade of receptors.

Here we report an innovative method for fast and sensitive detection of extracellular GABA in brain tissue. We used a human 
embryonic kidney (HEK) cell line that stably expresses $\mathrm{GABA}_{\mathrm{A}}$ receptors that respond to GABA with a current that decays to a steady state. By recording one HEK cell with whole-cell patchclamp technique, we obtained a sniffer that transduces GABA into a measurable current. We demonstrate that the sniffer can be transferred into slices from the central nervous system where it can measure the concentration of ambient GABA and detect spillover. To the best of our knowledge, this is the first GABA sensor that combines both, the ability to detect fast transients and to measure steady concentrations.

\section{MATERIAL AND METHODS GABA SNIFFER}

Human embryonic kidney (HEK) cells 293 expressing GABA $_{A}$ receptors (gift from NeuroSearch A/S, Ballerup, Denmark) were grown in T75 flasks (VWR, Herlev, Denmark) in full DMEM media (DMEM supplemented with $100 \mathrm{U} / \mathrm{mL}$ penicillin, $100 \mathrm{mg} / \mathrm{ml}$ streptomycin, and 10\% fetal calf serum; (SigmaAldrich, Copenhagen, Denmark) at $37^{\circ} \mathrm{C}$, in a humidified atmosphere with $5 \% \mathrm{CO}_{2}$. Confluent cells were rinsed with phosphate buffered saline (in-house, University of Copenhagen), trypsinized (1\%) and plated on $9 \mathrm{~mm}$ coverslips (VWR). Cells were allowed to settle on coverslips for a minimum of 30 min before being transferred to a recording chamber, where they were positioned next to a spinal cord slice.

HEK cells were recorded in whole-cell configuration in voltageclamp mode. The recording pipette was mounted on a 3-axes motorized micromanipulator (Luigs and Neumann, Ratingen, Germany). Their membrane potential was held at $0 \mathrm{mV}$. The sensitivity of HEK cells to GABA was systematically tested by measuring the current evoked by a puff of GABA ( $1 \mathrm{mM}$; Sigma-Aldrich; see Figure 1).

\section{REVERSE TRANSCRIPTION (RT)-PCR}

Total RNA was prepared from HEK293 cells constitutively expressing $\mathrm{GABA}_{\mathrm{A}}$ receptors using the RNeasy Mini Kit (Qiagen, Hilden,
Germany) according to the manufacturer's instructions. The RNA was reverse-transcribed using a poly-T primer $\left(5^{\prime}-\mathrm{T} 24-\mathrm{V}-\mathrm{N}-3^{\prime}\right)$ and Superscript ${ }^{\mathrm{TM}}$ III according to the manufacturer's instructions (Invitrogen, Carlsbad, CA, USA). Controls were performed in the absence of template. The RT products were PCR amplified using PfuUltra II polymerase (Stratagene) and oligodeoxynucleotides primers for $\mathrm{GABA}_{\mathrm{A}}$ subunits (Table 1). The cycling conditions were $2 \mathrm{~min}$ at $94^{\circ} \mathrm{C} ; 25$ cycles at $94^{\circ} \mathrm{C}$ for $30 \mathrm{~s}$, annealing temperature differing between primer pairs (see Table 1) for $40 \mathrm{~s}, 72^{\circ} \mathrm{C}$ for $30 \mathrm{~s} ; 72^{\circ} \mathrm{C}$ for $5 \mathrm{~min}$. Amplified products were analyzed using $1 \%$ agarose gels. The PCR products were sequenced for identity confirmation (Macrogen Inc., Seoul, Republic of Korea).

\section{SLICE PREPARATION}

Adult turtles (Trachemys scripta elegans) were anesthetized by intravenous injection of propofol $(0.3 \mathrm{ml} / 100 \mathrm{~g}$; Propolipid Frenesius Kabi, Sweden) and killed by decapitation. The surgical procedures complied with Danish legislation. The spinal cord was removed after intra-cardiac perfusion of a high $\mathrm{Mg}^{2+}$ solution (in mM: $120 \mathrm{NaCl}, 5 \mathrm{KCl}, 15 \mathrm{NaHCO}_{3}, 20$ Glucose, $20 \mathrm{MgCl}_{2}$, $3 \mathrm{CaCl}_{2}$ ). All experiments were performed at room temperature $\left(20-22^{\circ} \mathrm{C}\right)$.

The lumbar enlargement (D8-S2) was cut into slices (300$1500 \mu \mathrm{m}$ thick) with a vibratome (MicroM slicer HM $650 \mathrm{~V}$; Microm International GmbH, Germany) equipped with cooling unit CU65 set at $2^{\circ} \mathrm{C}$. For some experiments, a dorsal root filament was left in continuity with the slice and mounted on a suction electrode connected to a stimulator. Slices were continuously perfused with Ringer's solution (in mM: $120 \mathrm{NaCl}, 5 \mathrm{KCl}, 15 \mathrm{NaHCO}_{3}, 20$ Glucose, $2 \mathrm{MgCl}_{2}, 3 \mathrm{CaCl}_{2}$ ) saturated with $98 \% \mathrm{O}_{2}$ and $2 \% \mathrm{CO}_{2}$ to obtain a $\mathrm{pH}$ of 7.6 .

\section{PATCH-CLAMP RECORDING}

Visually guided patch-clamp recordings were performed in wholecell configuration with a Multiclamp 700B amplifier (Molecular

\section{Table 1 | Primers and conditions for reverse-transcription PCR.}

\begin{tabular}{|c|c|c|c|c|c|}
\hline Subunit & GenBank Acc. No. & Primer Sequence $\left(5^{\prime}-3^{\prime}\right) ; \mathrm{T}_{\mathrm{m}}\left[{ }^{\circ} \mathrm{C}\right]$ & $\mathbf{T}_{\mathrm{ann}}\left[{ }^{\circ} \mathbf{C}\right]$ & amplicon [bp] & Ref \\
\hline$\alpha 1$ & NM_001127644.1 & F: TGAGCACACTGACTGGAAGAAGC; 62,4 & 55 & 999 & Maddox et al. (2004) \\
\hline \multirow[t]{2}{*}{$\alpha 6$} & NM_000811.2 & F: TGATGGTCAGTAAAATCTGGACGC; 61,0 & 55 & 507 & Maddox et al. (2004) \\
\hline & & R: AAACAGTTCTTGCTGGGACGG-3'; 59,8 & & & \\
\hline$\beta 2$ & NM_021911.2 & F: TGCCTGATACCTATTTCCTGAACG-3'; 61,0 & 55 & 488 & Maddox et al. (2004) \\
\hline \multirow[t]{2}{*}{$\delta$} & NM_000815.4 & F: AGGACATCGTCTACTACTGGTCGGAGAG-3'; 64,4 & 55 & 439 & Maddox et al. (2004) \\
\hline & & R:TCGGCGTTGAAATGAGCAAAGG-3'; 60,3 & & & \\
\hline \multirow[t]{2}{*}{$\gamma^{2}$} & NM_198904.2 & F: TGCACACTCATTGTCGTCCTATCCTGG-3'; 66,5 & 60 & 524 & Maddox et al. (2004) \\
\hline & & R: TTAAACAGGCAGAAGGCAGTGGGG-3'; 64,4 & & & \\
\hline
\end{tabular}

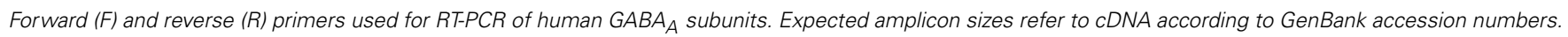


A

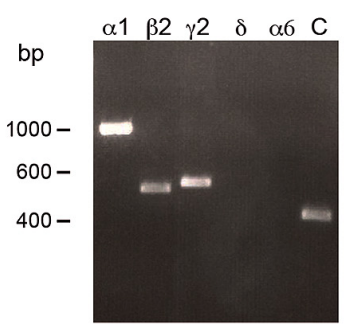

B

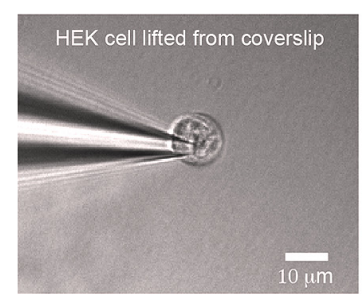

c

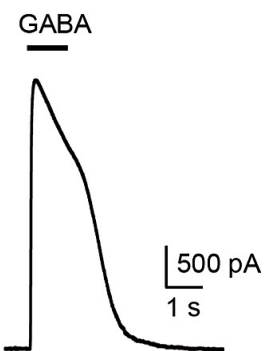

D1

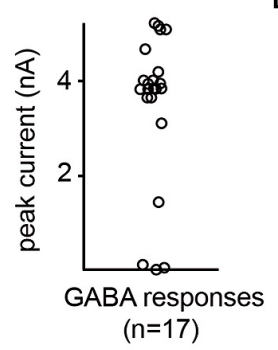

D2

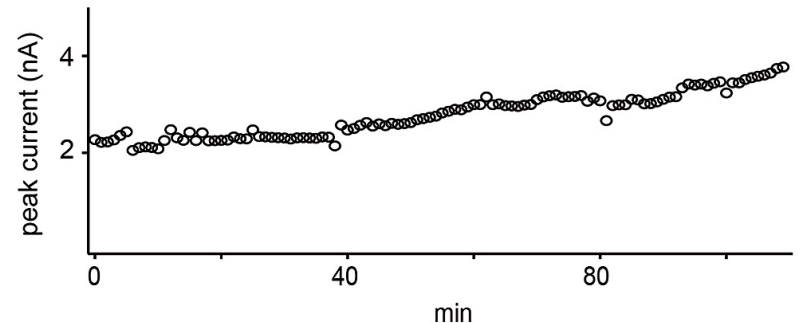

E
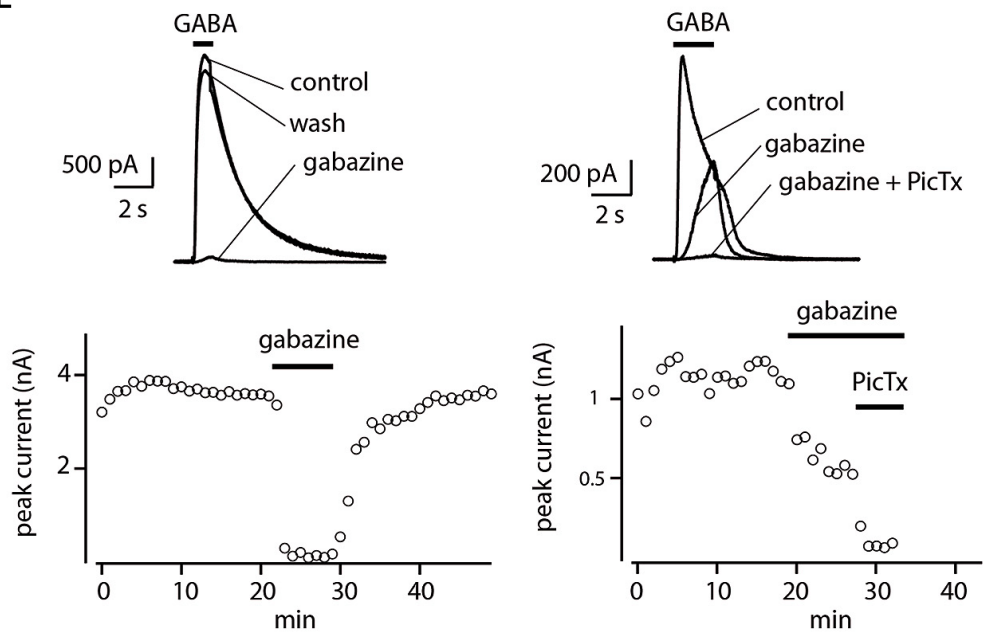

FIGURE 1 | Whole-cell sniffer with $\mathrm{GABA}_{\mathbf{A}}$ receptors. (A) RT-PCR verifying the expression of $\mathrm{GABA}_{A}$ receptors composed of $\alpha 1 \beta 2 \gamma 2$ subunits in HEK cells. Primers for $\alpha 6$ and $\delta$ subunits were included as control. Expression of hGAPDH served as control (C) of cDNA quality.

(B) Whole-cell recording of a HEK cell detached from the coverslip. (C) A single puff of GABA evoked a large outward current. (D1) Distribution of

Devices, USA) in voltage-clamp mode. Cells were visualized by means of a BW51WI microscope (Olympus, Japan) equipped with an oblique illumination condenser or with a differential interference contrast system. The pipette solution (in mM: $122 \mathrm{~K}$ gluconate, $2.5 \mathrm{MgCl}_{2}$, $5.6 \mathrm{Mg}$-gluconate, $5 \mathrm{~K}$-HEPES, $5 \mathrm{H}$-HEPES, $5 \mathrm{Na}_{2} \mathrm{ATP}, 1$ EGTA, 2.5 biocytine, $\mathrm{HCl}$ to adjust the $\mathrm{pH}$ to 7.4) contained the fluorescent dye Alexa $488(250 \mu \mathrm{M}$, Sigma-Aldrich). Electrodes had an input resistance ranging from 4 to $8 \mathrm{M} \Omega$. Recordings were sampled at $10-20 \mathrm{kHz}$ and treated offline with a Bessel filter with a cutoff frequency set at $400 \mathrm{~Hz}$. Data were sampled with a 16-bit analog-to-digital converter (DIGIDATA 1440;

Molecular Devices, USA) and displayed by means of Clampex 10.2 software (Molecular Devices, USA). Data are presented without liquid-junction potential correction unless specified.

\section{FOCAL APPLICATION OF DRUGS}

Electrodes made from borosilicate capillaries with tip diameter $<1.5 \mu \mathrm{m}$ (G150F-3; Warner Instruments, USA) were filled either with GABA ( $1 \mathrm{mM}$ in Ringer's solution) or glutamate ( $1 \mathrm{mM}$ in Ringer's solution; Sigma-Aldrich). Drugs were puff applied at 14-35 $\mathrm{Pa}$ by a homemade time-controlled pressure device. 


\section{GLUTAMATE UNCAGING}

Caged glutamate (MNI-caged-L-glutamate; $10 \mu \mathrm{M}$; Tocris Bioscience, UK) was added to the bath. Glutamate was uncaged at different points of interest (POI) by means of an UGA 40 scanning system generating light spots with a diameter of $\sim 5 \mu \mathrm{m}$ coupled to a $375 \mathrm{~nm}$ laser (Rapp OptoElectronic GmbH, Wedel, Germany).

\section{STATISTICAL ANALYSIS}

Data were analyzed by means of IGOR Pro 6.22 (Wavemetrics, Tigard, OR, USA) and Matlab (MathWorks; Natick, MA, USA). The normality of distribution of each sample was tested with One Sample Kolmogorov-Smirnov test. Non-parametric tests were used when Gaussian distribution could not be approximated. Data are represented as median \pm standard deviation. Mean \pm standard error (SE) is used when indicated.

\section{DRUGS}

The following drugs were used: glutamate (Sigma-Aldrich), $\gamma$-Aminobutyric acid (Sigma-Aldrich), MNI-caged-L-glutamate (Tocris Bioscience, Abingdon, UK), Tetrodotoxin (TTX; Alomone Labs, Jerusalem, Israel), SR 95531 hydrobromide (gabazine, Tocris Bioscience), Picrotoxin (Tocris Bioscience).

\section{RESULTS}

\section{HEK293 CELL LINE PROPERTIES}

We verified that the HEK cell line expressed $\alpha 1, \beta 2$, and $\gamma 2$ subunits of the $\mathrm{GABA}_{\mathrm{A}}$ receptor by performing non-quantitative RT-PCR using primers described by Maddox et al. (2004). Amplicons of the expected molecular sizes were obtained for $\alpha 1, \beta 2$, and $\gamma 2$ subunits. We used primer pairs for $\alpha 6$ and $\delta$ subunits as negative controls, and as expected, none of these subunits were present in the cell line (Figure 1A). As additional negative control, we performed the reactions in the absence of template DNA (data not shown). The expression of the housekeeping gene GAPDH served as control of the quality of the prepared cDNA. The identity of PCR-products was confirmed by sequencing.

HEK 293 cells were plated on coverslips and moved to a recording chamber continuously perfused with Ringer's solution. We measured how the cells responded to saturating concentrations of GABA by recording them with the patch-clamp technique in whole-cell configuration in voltage-clamp mode (holding potential $V_{\mathrm{h}}=0 \mathrm{mV}$; Figure 1B). In our experimental conditions, we calculated a reversal potential for chloride ions of $-71.8 \mathrm{mV}$. We found that an $1 \mathrm{~s}$ puff $(14-35 \mathrm{~Pa})$ of high concentration of GABA $(1 \mathrm{mM})$ applied through a glass pipette positioned at a distance of $20-30 \mu \mathrm{m}$, induced a strong outward current (median amplitude: $3941 \pm 961 \mathrm{pA} ; n=17$; Figures 1C,D1) with a reversal potential of $-67 \pm 14 \mathrm{mV}(n=7$; Figure 2A). The conductance of single $\alpha 1 \beta 2 \gamma 2 \mathrm{GABA}_{\mathrm{A}}$ receptor is in the range of 19-26 pS. Using Ohm's low, we approximated that each sniffer contains $3000-4200 \mathrm{GABA}_{\mathrm{A}}$ receptors. The rise time of the current estimated as the duration from 20 to $80 \%$ of the peak current varied from 11.4 to $40.3 \mathrm{~ms}$, corresponding to a median rate of rise of $114 \pm 96 \mathrm{pA} / \mathrm{ms}$. The majority of cells responded to GABA since only 3/17 $(17.6 \%)$ remained silent during puff application. The evoked responses were remarkably stable. Consecutive puff applications of GABA over more than $1 \mathrm{~h}$ evoked responses that did not decrease in amplitude (Figure 1D2; $n=2$ ). The evoked currents were reversibly inhibited by gabazine $(10 \mu \mathrm{M}$; two out of four trials; Figure 1E). In some instances, gabazine alone was not sufficient to eliminate the evoked current. However, after addition of the $\mathrm{GABA}_{\mathrm{A}}$ receptor blocker picrotoxin $(50 \mu \mathrm{M})$ the response was always abolished (Figure 1E; $n=3$ ). To
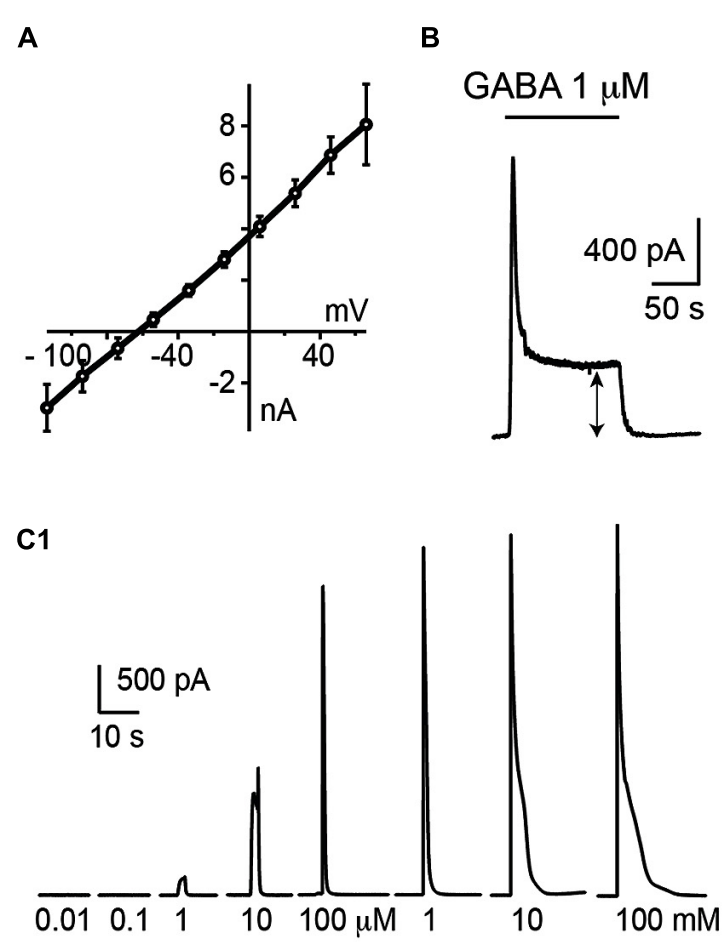

C2

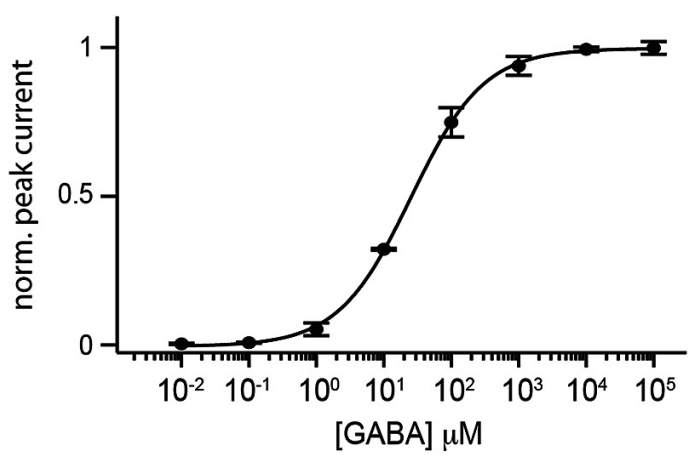

FIGURE 2 | Electrophysiological properties of the whole-cell sniffer. (A) IN plot of sniffer responses to GABA (1 mM) from 7 cells clamped from -120 to $80 \mathrm{mV}$. Values were corrected for liquid junction potential. The average reversal potential ( $\mathrm{E}_{\mathrm{GABA}}$ ) was of $-67 \mathrm{mV}$. (B) Response of a sniffer to a prolonged exposure of GABA. The sniffer exhibited a non-inactivating component (double arrow). (C1) Responses of a sniffer to $1 \mathrm{~s}$ puff of increasing GABA concentrations (from $0.01 \mu \mathrm{M}$ to $100 \mathrm{mM}$ ). (C2) Hill plot of dose-responses relationships of peak currents ( $r=0.99994)$.

Responses were normalized to the fitted /max value. The average $\mathrm{EC}_{50}$ for the peak response was $26.3 \pm 3.0 \mu \mathrm{M}$ (mean $\pm \mathrm{SE} ; n=3$ ). 
further characterize the sniffer, we established a concentrationresponse relationship by puffing different concentrations of GABA. We found that the amplitude of the current increased with the concentration of GABA (Figure 2C1). By fitting a Hill equation to the normalized amplitude of the current as a function of the GABA concentration $(r=0.99994)$, we determined a half maximal effective concentration $\left(\mathrm{EC}_{50}\right)$ of $26.3 \pm 5.2 \mu \mathrm{M}$ with Hill coefficient of $0.8 \pm 0.02(n=3$; Figure 2C2).

During prolonged applications of GABA, the sniffer exhibited fast desensitization with decay time constants $(t)$ ranging from 0.8 to $4.8 \mathrm{~s}$. However, a significant component corresponding to approximately one fifth $(18 \pm 12 \% ; n=5)$ of the maximal response did not desensitize (Figure 2B). The remaining tonic current had an amplitude that increased with the concentration of GABA. Since the sniffer generated a persistent current, we investigated if this enabled us to estimate the ambient concentration of GABA inside nervous tissue.

\section{DETECTION OF AMBIENT GABA CONCENTRATION IN A SLICE PREPARATION}

To measure the extracellular GABA concentration in the central nervous system, we positioned a coverslip with HEK cells near a slice preparation from the spinal cord. We recorded one HEK cell in whole-cell configuration and moved it to the surface of the spinal cord by means of a motorized micromanipulator (Figure 3A1). The membrane resistance was continuously monitored. When lowering the sniffer to the surface of the slice, we often recorded large steady-state outward currents (up to $\sim 500 \mathrm{pA}$ ) and a concomitant increase in electrical noise (Figure 3A1). A fast Fourier transform analysis revealed that the frequencies below $500 \mathrm{~Hz}$ were strengthened (Figure 3A2). This probably reflects the stochastic fluctuations in the $\mathrm{GABA}_{\mathrm{A}}$ receptor channels opening and closing (Mtchedlishvili and Kapur, 2006) which generate a noise in the band from 0 to $200 \mathrm{~Hz}$ (Kaneda et al., 1995; Brickley et al., 1996; Figure 3A2). The amplitude of the current varied with the distance between the slice surface and the sniffer. The first signs of tonic currents were usually detected at a distance of approximately $50 \mu \mathrm{m}$ above the slice and increased to a maximum when touching the surface of the slice tissue. At this stage, the sniffer cell was slowly moved down in the tissue at a speed of around $1 \mu \mathrm{m} / \mathrm{s}$. The progression was stopped as soon as the membrane resistance decreased more than $10 \%$. Using this procedure it was possible to reach depths of $80 \mu \mathrm{m}$ without losing the recording. The sniffer also detected GABA inside the slice. The currents recorded were not stronger than just above the surface. To quantify the actual concentration of GABA in the slice, we withdrew the sniffer and positioned it at a distance where no current was detected (i.e., at least $500 \mu \mathrm{m}$ above the slice). We then applied increasing concentrations of GABA (ranging from 0.01 to $10 \mu \mathrm{M}$ ) in the bath and measured the evoked steady state currents (Figure 3B1). By fitting a Hill equation to the amplitude of the steady-state current as function of the GABA concentration, we obtained a standard concentration-response curve ( $r=0.9998$; Figure 3B2). We used the curve to estimate the GABA concentration in relation to measured currents. Finally, a second measurement was performed at the surface of the slice to confirm the value obtained with the first measurement. In the example illustrated in Figure 3B1, we measured a current of $41.9 \mathrm{pA}$ in the slice. This corresponded to an average concentration of $0.232 \mu \mathrm{M}$ on the Hill plot (Figure 3B2). Repeating the procedure after calibration confirmed our first estimation $(44.8 \mathrm{pA}$ corresponding to $0.242 \mu \mathrm{M})$. We calibrated the sniffer for the experiments performed in two slices. The sniffer detected ambient GABA in both slices, with a mean concentration of $0.176 \mu \mathrm{M}$. In slices made from 2 of the 11 animals, we did not detect a tonic GABA signal. The sensitivity of our equipment allows us to measure currents as low as $10 \mathrm{pA}$, corresponding to a GABA concentration of $0.1 \mu \mathrm{M}$. The lack of tonic current indicates that the ambient concentration of GABA is below this value. Next, we tested if the level of ambient GABA depended on neuronal activity. For this purpose we added the sodium ion channel blocker tetrodotoxin (TTX; $10 \mu \mathrm{M} ; n=1$ ) to the extracellular medium. In the example of Figure 3, the steady state current of the sniffer dropped to $14.6 \mathrm{pA}$, corresponding to a GABA concentration of $0.124 \mu \mathrm{M}$ (Figures 2 and 3B1). This test, which confirms that the tonic current recorded in the sniffer is not caused by an artifact, suggests that a substantial fraction of the ambient GABA has a neuronal origin. However, more systematic experiments are required to confirm this preliminary observation.

\section{DETECTION OF GABA TRANSIENTS IN A SLICE PREPARATION}

When the sniffer was positioned inside the slice, we sometimes recorded spontaneous transient outward currents (Figure 4B1). They had a rise time of $12.9 \pm 49 \mathrm{~ms}$ (measured from 20 to $80 \%$ of the maximal amplitude) and decayed with a time constant of $98 \pm 267 \mathrm{~ms}$ (Figure 4D). Their rate of rise was $4.2 \pm 3.5 \mathrm{pA} / \mathrm{ms}$. These observations showed that extracellular GABA concentration varied phasically. Next, we evoked GABA release in the extrasynaptic space, either by puffing glutamate $(1 \mathrm{mM})$ through a glass pipette (Figures $4 \mathrm{~A}, \mathrm{B3}$ ) or by photolysing caged-glutamate in the vicinity of the sniffer cell (Figures 4A,B2). Both techniques evoked outward currents in the sniffer demonstrating that glutamate induces GABA release in the extrasynaptic compartment. The events evoked by puffing glutamate had rise times ranging from 0.6 to $65 \mathrm{~ms}$ (median $12.0 \pm 18 \mathrm{~ms}$ ) and a median rate of rise of $13.6 \pm 22.8 \mathrm{pA} / \mathrm{ms}$. The events induced by uncaging glutamate were slightly slower $(4.2 \pm 3.5 \mathrm{pA} / \mathrm{ms})$. Since the rate of rise of events evoked by saturating concentrations of GABA were one order of magnitude faster $(114.1 \pm 96.7 \mathrm{pA} / \mathrm{ms}$; Figure 1C), we can assume that the intrinsic properties of the sniffer were not a limiting factor for detecting transients. Our observations suggest instead that the measured transients reflected the actual local changes in GABA concentration that occurred near the sniffer. To confirm that the phasic events reflected variations in GABA concentrations, we added gabazine $(20 \mu \mathrm{M})$ or picrotoxin $(50 \mu \mathrm{M})$ to the extracellular medium. As expected, it eliminated all the events (Figure 4B3).

Next, we tested if the sniffer was sensitive enough for detecting release of GABA evoked by synaptic activation. For this purpose, we used a spinal cord preparation in which a dorsal root filament was left intact. We stimulated primary afferents by means of a suction electrode (Figure 4C1). A single electrical chock 


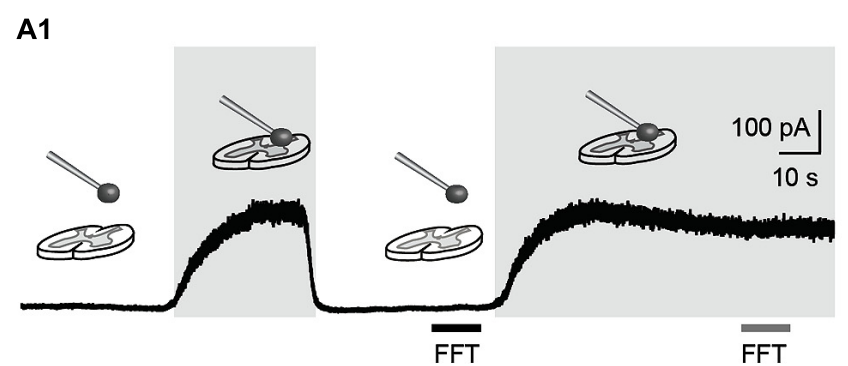

A2

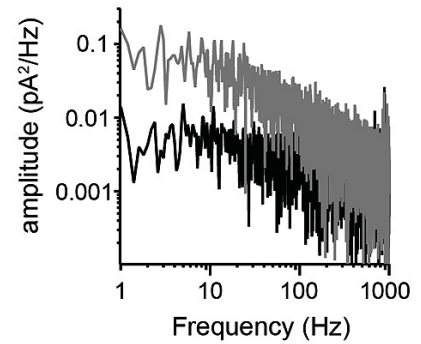

B1

B2
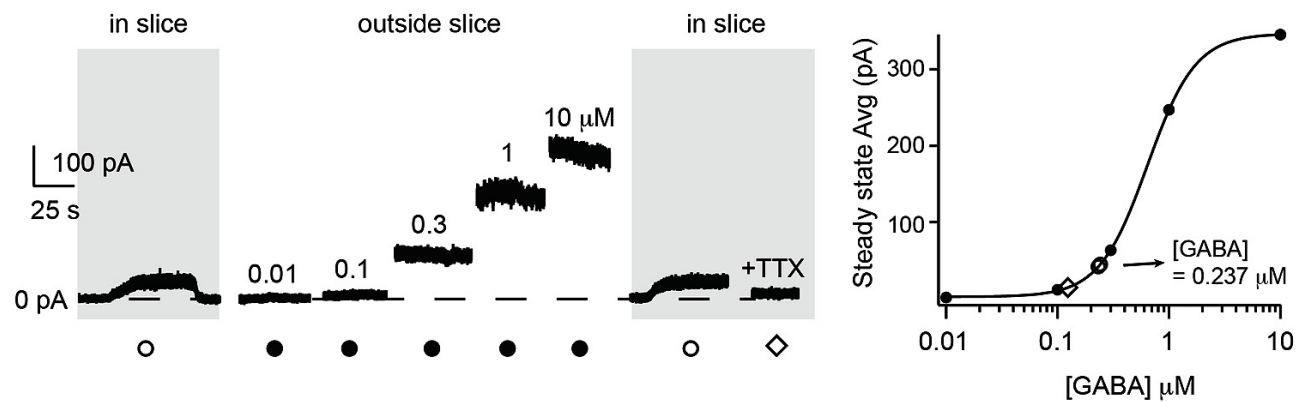

FIGURE 3 | Detection and quantification of ambient GABA in a slice preparation. (A1) Response of a sniffer at different positions above a slice preparation from the spinal cord. Positioning the sniffer at the slice surface evoked a persistent outward current and increased the noise of the recording. Both current and noise disappeared when the sniffer was moved $500 \mu \mathrm{m}$ above the slice. The gray and black horizontal bars indicate the time intervals used for Fast Fourier Transformation (FFT) analysis in A2. (A2) Power spectrum densities of the current measured by the sniffer far from the slice (black) and on the surface (gray). The frequencies between 1 and $1000 \mathrm{~Hz}$ were stronger when the sniffer was just above the surface of the slice. (B1) Response of a sniffer positioned in a slice (gray background) or outside the slice (white background). The responses far from the slice were evoked by applying incremental GABA concentrations in the extracellular medium. TTX $(50 \mathrm{nM})$ was added in the end of the experiment. (B2) Hill plot of concentration-response relationship of steady state currents evoked by GABA in the extracellular medium. The two open circles represent the measurements from the surface of the slice before and after calibration. The average concentration of GABA obtained from the curve was of $0.237 \mu \mathrm{M}$. The open diamond represents the measurement obtained in TTX.
(40 $\mu \mathrm{A}, 700 \mu \mathrm{s})$ evoked transient outward currents in a sniffer positioned $80 \mu \mathrm{m}$ below the surface of the dorsal horn $(n=3$; Figure 4C2). The response was abolished after blockade of voltage sensitive sodium channels with tetrodotoxin ( $50 \mathrm{nM}$; Figure 4C2). This result suggests that the activity of sensory afferents induces a release of GABA in the extrasynaptic space and demonstrates that our sniffer is sensitive enough to detect it.

\section{DISCUSSION}

We have demonstrated a novel method for measuring the ambient GABA and detecting variations in concentrations during neuronal activity. Our approach has several important advantages. First, the sniffer detects GABA with a temporal resolution in the order of $1 \mathrm{~ms}$. In comparison, the detection rates achieved with other techniques such as microdialysis combined with HPLC or liquid chromatography-tandem mass spectrometry after butylation are on the order of minutes (Maddox et al., 2004; de Groote and Linthorst, 2007; Vanini et al., 2011). When saturating GABA concentrations were applied, the rates of rise of the evoked responses were significantly faster than the currents measured in slices. This suggests that we were able to detect local GABA concentration changes in real time. To our knowledge, this has never been reported before. Second, the sensitivity of the sniffer is reasonable since we were able to detect responses in the sniffer with ambient GABA concentrations as low as $0.1 \mu \mathrm{M}$. In excised outside-out patch made from central neurons, few receptors are present and it is not possible to establish a concentration-response relationship (Isaacson et al., 1993; Banks and Pearce, 2000; Gao and Van Den Pol, 2000; Liu et al., 2005). Third, the measurements of ambient GABA were reproducible. Moving the sniffer up and down a slice gave similar results. When the sniffer was calibrated it was possible to obtain accurate measurements of GABA concentration. Fourth, the sniffer allows detection of GABA without any pharmacological intervention. Detecting GABA with outside-out patch made from central neurons requires the blockade of receptors from other neurotransmitters such as glutamate, glycine, or acetylcholine (Isaacson et al., 1993; Liu et al., 2005). Employing the respective inhibitors will in turn affect the activity of the neuronal network. Ambient GABA and spillover are commonly studied with the help of pharmacological agents that isolate extrasynaptic receptors (Nusser and Mody, 2002) or block of GABA uptake mechanisms (Isaacson et al., 1993; Scanziani, 2000; Song et al., 2011). Our sensor is sufficiently sensitive to measure ambient GABA and to detect release in the extrasynaptic space with normal extracellular medium. Fifth, the sniffer has a small size (diameter below $10 \mu \mathrm{m}$ ). This allows for GABA detection 
A
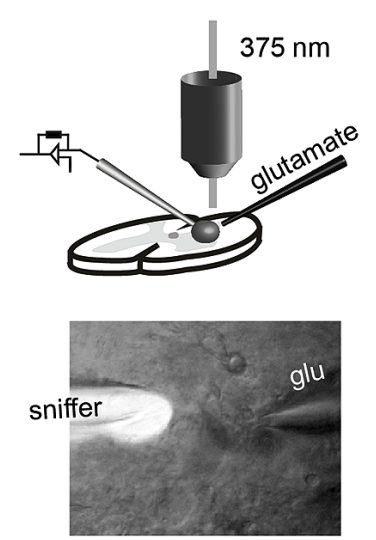

C1
B1

\section{spontaneous}

\begin{tabular}{l|l}
$100 \mathrm{pA}$
\end{tabular}

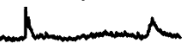

B2

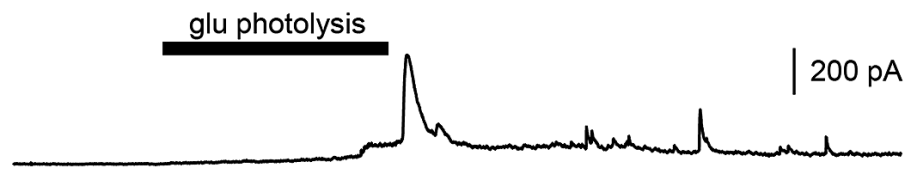

B3
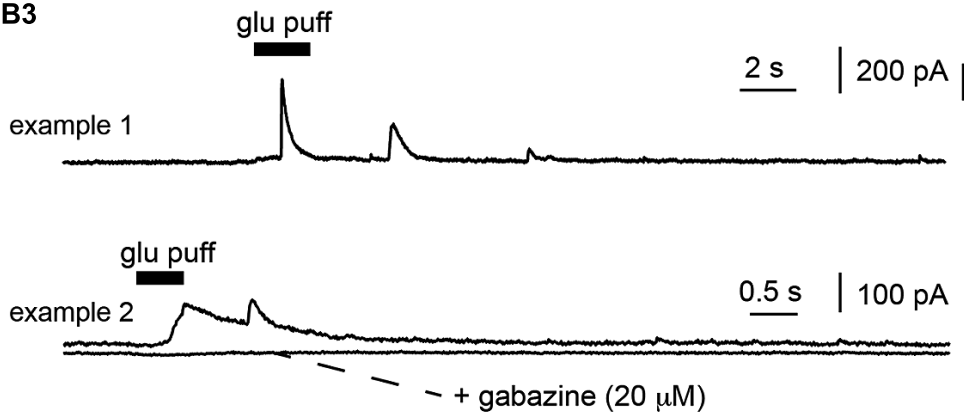

C2

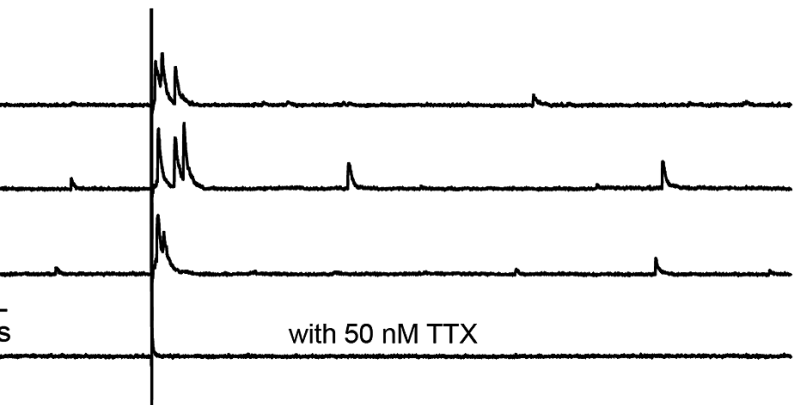

$0.7 \mathrm{~ms}$

几

$100 \mathrm{pA}$

$0.2 \mathrm{~s}$

D

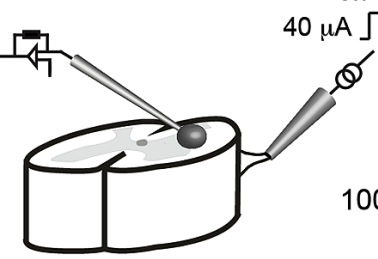

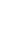
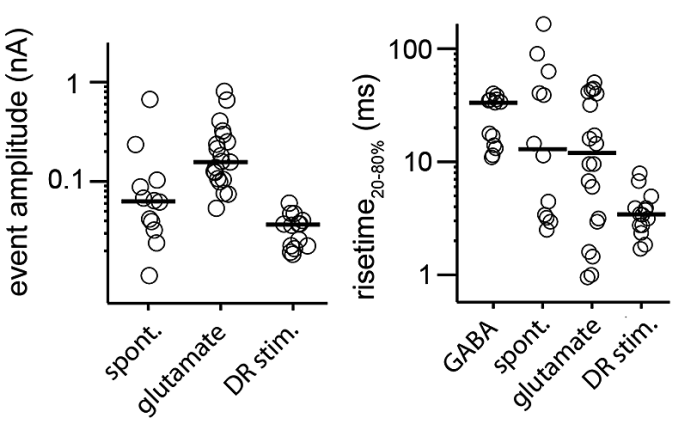

FIGURE 4 | Detection of GABA transients in a slice preparation.

(A) Illustration of the experimental setup. GABA release was evoked either by puffing glutamate or uncaging glutamate with a $375 \mathrm{~nm}$ laser. The lower picture illustrates a sniffer filled with the fluorophore Alexa 488 (white) placed inside a slice from the spinal cord. The pipette coming from the right was used to puff glutamate (glu). (B) Examples of transient events recorded in the sniffer. (B1) Spontaneous events. (B2) Events evoked by glutamate uncaging. (B3) Events evoked by glutamate puff. The responses were abolished after addition of the $\mathrm{GABA}_{A}$ receptor antagonist gabazine $(20 \mu \mathrm{M})$. (C1) Scheme of the preparation. Slice from the spinal cord with a dorsal root filament

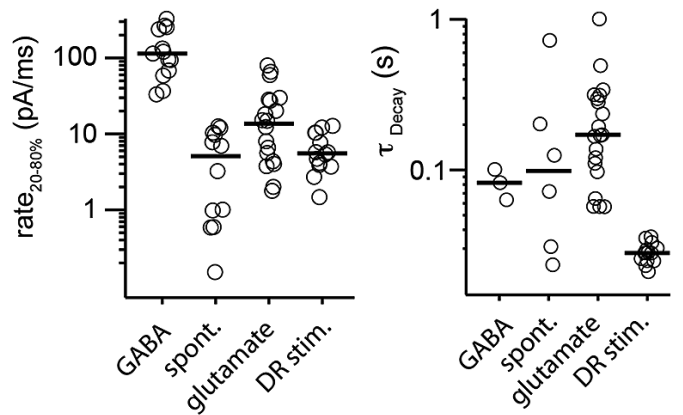

stimulated with a suction electrode. Sniffer positioned in the slice. (C2) Response of the sniffer to single shocks applied on the dorsal root filament. Dorsal root stimulation evoked transient release of GABA. The responses were abolished after addition of TTX (50 nM). (D) Characteristics of the different types of events recorded by the sniffer (evoked by GABA, spontaneous, evoked by glutamate or dorsal root stimulation). From left to right: amplitude; rise time of the rising phase (from 20 to $80 \%$ of peak); rate of rise calculated as current from 20 to $80 \%$ of peak divided by rise time from 20 to $80 \%$ of the peak; time constant $(\tau)$ of the of the decay estimated by fitting a single exponential function. 
in the proximity of GABA sources (e.g., synapses). In contrast, microdialysis probes have a diameter of more than a millimeter (Reynolds et al., 1999) and are not adapted for local detection of transmitters.

The method we developed also has limitations. Importantly, we cannot use the sniffer for recording deep in brain tissue. During our trials, we managed to position the sniffer down to $80 \mu \mathrm{m}$ below the surface of slices. Attempts of moving deeper resulted in irreversible damages. However, we performed our experiments in slices from an adult vertebrate, which is heavily myelinated. It is likely that trials performed with embryonic or neonate nervous tissue containing little myelin would allow deeper recordings. Another disadvantage lies in the fact that the sniffer has to be calibrated for each experiment if one wants to quantify the concentration of GABA. This requires withdrawing the sniffer from the tissue before applying series of GABA concentrations in the bath. This procedure is difficult when the sniffer has been in the slice for several minutes. The seal between the recording electrode and the HEK cell often breaks at this stage. Finally, the sensitivity of our sniffer allowed us to detect concentrations in the order of $100 \mathrm{nM}$ (see Figure 3B). This is not the most sensitive method available for measuring GABA concentration. Studies using microdialysis combined with HPLC reported concentrations as low as 1-10 nM (Rowley et al., 1995; Rea et al., 2005).

\section{INTERPRETATION OF RECORDINGS}

The local concentration of GABA decays as a function of the distance between the source and the probe used to detect it. Diffusion of GABA in the extrasynaptic space also affects the time course of GABA transients: the more remote the source, the slower the kinetic (Allen, 1997). During our experiments, we observed transient events with slow rise times ( $>10 \mathrm{~ms})$ compared to fast IPSCs $(<1 \mathrm{~ms})$ measured in post-synaptic neurons (Korshoej et al., 2010; Xie and Manis, 2013). This observation can be interpreted in two ways: (1) the source of GABA was distant from the sniffer; (2) The release of GABA occurs through a slow process, such as diffusion through cation channels (Song et al., 2011) or via the reversal of a GABA transporter (Reynolds et al., 1999). It is unlikely that the intrinsic properties of the sniffer contributed to shaping of transient events because it could react to high concentrations of GABA with much faster kinetics $(\sim 100 \mathrm{pA} / \mathrm{ms})$ than the events detected in the tissue $(\sim 10 \mathrm{pA} / \mathrm{ms})$.

\section{PERSPECTIVE}

The presence of an ambient GABA concentration in the extracellular space of the brain is well accepted (Farrant and Nusser, 2005). However, the origin of GABA remains controversial. Some studies suggest that most of the ambient GABA originates from neuronal vesicular release (Brickley et al., 1996). Other publications indicate that the extracellular GABA has a non-vesicular source (Wall and Usowicz, 1997; Rossi et al., 2003). Recent investigations proposed that the extracellular GABA could also have a glial origin (Lee et al., 2010; Le Meur et al., 2012). Our technique could prove useful for identifying the cells that release GABA in the extrasynaptic space. Another challenge will be to apply this technique in vivo.
Even though it appears technically challenging, we believe that it is feasible.

\section{AUTHOR CONTRIBUTIONS}

Rasmus K. Christensen and Jean-François Perrier, conception and design of research. Nicole Schmitt, supervision of molecular biology. Rasmus K. Christensen and Anders V. Petersen, performed experiments. Rasmus K. Christensen analyzed data. Rasmus K. Christensen and Jean-François Perrier interpreted results of experiments. Rasmus K. Christensen and Jean-François Perrier wrote the manuscript. Rasmus K. Christensen, Anders V. Petersen, Nicole Schmitt and Jean-François Perrier approved final version of manuscript.

\section{ACKNOWLEDGMENTS}

The project was funded by the Owensenske Fond, Simon Fougner Hartmanns Familiefond, Agnes, and Poul Friis Fond, Novo Scholarship Programme and the Carlsberg Foundation.

\section{REFERENCES}

Alle, H., and Geiger, J. R. (2007). GABAergic spill-over transmission onto hippocampal mossy fiber boutons. J. Neurosci. 27, 942-950. doi: 10.1523/JNEUROSCI.4996-06.2007

Allen, T. G. (1997). The 'sniffer-patch' technique for detection of neurotransmitter release. Trends Neurosci. 20, 192-197. doi: 10.1016/S0166-2236(96) 01039-9

Banks, M. I., and Pearce, R. A. (2000). Kinetic differences between synaptic and extrasynaptic GABA(A) receptors in CA1 pyramidal cells. J. Neurosci. 20, 937948.

Bautista, W., Aguilar, J., Loeza-Alcocer, J. E., and Delgado-Lezama, R. (2010). Pre- and postsynaptic modulation of monosynaptic reflex by GABAA receptors on turtle spinal cord. J. Physiol. 588, 2621-2631. doi: 10.1113/jphysiol.2010. 188979

Benes, F. M., and Berretta, S. (2001). GABAergic interneurons: implications for understanding schizophrenia and bipolar disorder. Neuropsychopharmacology 25, 1-27. doi: 10.1016/S0893-133X(01)00225-1

Bolteus, A. J., Garganta, C., and Bordey, A. (2005). Assays for measuring extracellular GABA levels and cell migration rate in acute slices. Brain Res. Brain Res. Protoc. 14, 126-134. doi: 10.1016/j.brainresprot.2004.12.005

Brickley, S. G., Cull-Candy, S. G., and Farrant, M. (1996). Development of a tonic form of synaptic inhibition in rat cerebellar granule cells resulting from persistent activation of GABAA receptors. J. Physiol. 497(Pt 3), 753-759.

Bright, D. P., Renzi, M., Bartram, J., McGee, T. P., Mackenzie, G., Hosie, A. M., et al. (2011). Profound desensitization by ambient GABA limits activation of delta-containing GABAA receptors during spillover. J. Neurosci. 31, 753-763. doi: 10.1523/JNEUROSCI.2996-10.2011

Chance, F. S., Abbott, L. F., and Reyes, A. D. (2002). Gain modulation from background synaptic input. Neuron 35, 773-782. doi: 10.1016/S0896-6273(02) 00820-6

de Groote, L., and Linthorst, A. C. (2007). Exposure to novelty and forced swimming evoke stressor-dependent changes in extracellular GABA in the rat hippocampus. Neuroscience 148, 794-805. doi: 10.1016/j.neuroscience.2007. 06.030

Einarsen, K., Calloe, K., Grunnet, M., Olesen, S. P., and Schmitt, N. (2009). Functional properties of human neuronal Kv11 channels. Pflugers. Arch. 458, 689-700. doi: 10.1007/s00424-009-0651-5

Farrant, M., and Nusser, Z. (2005). Variations on an inhibitory theme: phasic and tonic activation of GABA(A) receptors. Nat. Rev. Neurosci. 6, 215-229. doi: 10.1038/nrn1625

Feucht, M., Fuchs, K., Pichlbauer, E., Hornik, K., Scharfetter, J., Goessler, R., et al. (1999). Possible association between childhood absence epilepsy and the gene encoding GABRB3. Biol. Psychiatry 46, 997-1002. doi: 10.1016/S00063223(99)00039-6 
Gao, X. B., and Van Den Pol, A. N. (2000). GABA release from mouse axonal growth cones. J. Physiol. 523(Pt 3), 629-637. doi: 10.1111/j.1469-7793.2000.t011-00629.x

Hamann, M., Rossi, D. J., and Attwell, D. (2002). Tonic and spillover inhibition of granule cells control information flow through cerebellar cortex. Neuron 33 625-633. doi: 10.1016/S0896-6273(02)00593-7

Huang, M., Li, Z., Dai, J., Shahid, M., Wong, E. H., and Meltzer, H. Y. (2008). Asenapine increases dopamine, norepinephrine, and acetylcholine efflux in the rat medial prefrontal cortex and hippocampus. Neuropsychopharmacology 33, 2934-2945. doi: 10.1038/npp.2008.20

Ingham, N. J., and McAlpine, D. (2005). GABAergic inhibition controls neural gain in inferior colliculus neurons sensitive to interaural time differences. J. Neurosci. 25, 6187-6198. doi: 10.1523/JNEUROSCI.0146-05.2005

Isaacson, J. S., Solis, J. M., and Nicoll, R. A. (1993). Local and diffuse synaptic actions of GABA in the hippocampus. Neuron 10, 165-175. doi: 10.1016/08966273(93)90308-E

Juhasz, G., Kekesi, K. A., Nyitrai, G., Dobolyi, A., Krogsgaard-Larsen, P., and Schousboe, A. (1997). Differential effects of nipecotic acid and 4,5,6,7tetrahydroisoxazolo[4,5-c]pyridin-3-ol on extracellular gamma-aminobutyrate levels in rat thalamus. Eur. J. Pharmacol. 331, 139-144. doi: 10.1016/S00142999(97)01044-3

Kaneda, M., Farrant, M., and Cull-Candy, S. G. (1995). Whole-cell and singlechannel currents activated by GABA and glycine in granule cells of the rat cerebellum. J. Physiol. 485 ( Pt 2), 419-435.

Kekesi, K. A., Dobolyi, A., Salfay, O., Nyitrai, G., and Juhasz, G. (1997). Slow wave sleep is accompanied by release of certain amino acids in the thalamus of cats. Neuroreport 8, 1183-1186. doi: 10.1097/00001756-199703240-00025

Kennedy, R. T., Thompson, J. E., and Vickroy, T. W. (2002). In vivo monitoring of amino acids by direct sampling of brain extracellular fluid at ultralow flow rates and capillary electrophoresis. J. Neurosci. Methods 114, 39-49. doi 10.1016/S0165-0270(01)00506-4

Korshoej, A. R., Holm, M. M., Jensen, K., and Lambert, J. D. (2010). Kinetic analysis of evoked IPSCs discloses mechanism of antagonism of synaptic GABAA receptors by picrotoxin. Br. J. Pharmacol. 159, 636-649. doi: 10.1111/j.14765381.2009.00542.x

Le Meur, K., Mendizabal-Zubiaga, J., Grandes, P., and Audinat, E. (2012) GABA release by hippocampal astrocytes. Front. Comput. Neurosci. 6:59. doi: 10.3389/fncom.2012.00059

Lee, S., Yoon, B.-E., Berglund, K., Oh, S.-J., Park, H., Shin, H.-S., et al. (2010) Channel-mediated tonic GABA release from glia. Science 330, 790-796. doi: $10.1126 /$ science. 1184334

Lerma, J., Herranz, A. S., Herreras, O., Abraira, V., and Martin Del Rio, R. (1986). In vivo determination of extracellular concentration of amino acids in the rat hippocampus. A method based on brain dialysis and computerized analysis. Brain Res. 384, 145-155. doi: 10.1016/0006-8993(86)91230-8

Ling, W., Shoptaw, S., and Majewska, D. (1998). Baclofen as a cocaine anti-craving medication: a preliminary clinical study. Neuropsychopharmacology 18, 403-404. doi: 10.1016/S0893-133X(97)00128-0

Liu, X., Wang, Q., Haydar, T. F., and Bordey, A. (2005). Nonsynaptic GABA signaling in postnatal subventricular zone controls proliferation of GFAP-expressing progenitors. Nat. Neurosci. 8, 1179-1187. doi: 10.1038/nn1522

Maddox, F. N., Valeyev, A. Y., Poth, K., Holohean, A. M., Wood, P. M., Davidoff, R. A. et al. (2004). GABAA receptor subunit mRNA expression in cultured embryonic and adult human dorsal root ganglion neurons. Brain Res. Dev. Brain Res. 149 143-151. doi: 10.1016/j.devbrainres.2004.01.001

Maex, R., and De Schutter, E. (1998). Synchronization of golgi and granule cell firing in a detailed network model of the cerebellar granule cell layer. J. Neurophysiol. 80, 2521-2537.

Mtchedlishvili, Z., and Kapur, J. (2006). High-affinity, slowly desensitizing GABAA receptors mediate tonic inhibition in hippocampal dentate granule cells. Mol. Pharmacol. 69, 564-575. doi: 10.1124/mol.105.016683

Numata, J. M., Van Brederode, J. F., and Berger, A. J. (2012). Lack of an endogenous GABAA receptor-mediated tonic current in hypoglossal motoneurons. J. Physiol. 590, 2965-2976. doi: 10.1113/jphysiol.2012.231944

Nusser, Z., and Mody, I. (2002). Selective modulation of tonic and phasic inhibitions in dentate gyrus granule cells. J. Neurophysiol. 87, 2624-2628.
Otis, T. S., Staley, K. J., and Mody, I. (1991). Perpetual inhibitory activity in mammalian brain slices generated by spontaneous GABA release. Brain Res. 545, 142-150. doi: 10.1016/0006-8993(91)91280-E

Rea, K., Cremers, T. I., and Westerink, B. H. (2005). HPLC conditions are critical for the detection of GABA by microdialysis. J. Neurochem. 94, 672-679. doi: 10.1111/j.1471-4159.2005.03218.x

Reynolds, N. C. Jr., Lin, W., Cameron, C. M., and Roerig, D. L. (1999). Extracellular perfusion of rat brain nuclei using microdialysis: a method for studying differential neurotransmitter release in response to neurotoxins. Brain Res. Brain Res. Protoc. 4, 124-131. doi: 10.1016/S1385-299X(99)00008-2

Rossi, D. J., Hamann, M., and Attwell, D. (2003). Multiple modes of GABAergic inhibition of rat cerebellar granule cells. J. Physiol. 548, 97-110. doi: 10.1113/jphysiol.2002.036459

Rowley, H. L., Martin, K. F., and Marsden, C. A. (1995). Determination of in vivo amino acid neurotransmitters by high-performance liquid chromatography with o-phthalaldehyde-sulphite derivatisation. J. Neurosci. Methods 57, 93-99. doi: 10.1016/0165-0270(94)00132-Z

Salin, P. A., and Prince, D. A. (1996). Spontaneous GABAA receptor-mediated inhibitory currents in adult rat somatosensory cortex. J. Neurophysiol. 75, 15731588.

Scanziani, M. (2000). GABA spillover activates postsynaptic GABA(B) receptors to control rhythmic hippocampal activity. Neuron 25, 673-681. doi: 10.1016/S08966273(00)81069-7

Song, I., Savtchenko, L., and Semyanov, A. (2011). Tonic excitation or inhibition is set by $\operatorname{GABA}(\mathrm{A})$ conductance in hippocampal interneurons. Nat. Commun. 2, 376. doi: 10.1038/ncomms 1377

Telgkamp, P., Padgett, D. E., Ledoux, V. A., Woolley, C. S., and Raman, I. M. (2004). Maintenance of high-frequency transmission at purkinje to cerebellar nuclear synapses by spillover from boutons with multiple release sites. Neuron 41 113-126. doi: 10.1016/S0896-6273(03)00802-X

Vanini, G., Wathen, B. L., Lydic, R., and Baghdoyan, H. A. (2011). Endogenous GABA levels in the pontine reticular formation are greater during wakefulness than during rapid eye movement sleep. J. Neurosci. 31, 2649-2656. doi: 10.1523/JNEUROSCI.5674-10.2011

Wall, M. J., and Usowicz, M. M. (1997). Development of action potential-dependent and independent spontaneous GABAA receptor-mediated currents in granule cells of postnatal rat cerebellum. Eur. J. Neurosci. 9, 533-548. doi: 10.1111/j.14609568.1997.tb01630.x

Wallace, R. H., Marini, C., Petrou, S., Harkin, L. A., Bowser, D. N., Panchal, R. G., et al. (2001). Mutant GABA(A) receptor gamma2-subunit in childhood absence epilepsy and febrile seizures. Nat. Genet. 28, 49-52. doi: 10.1038/ 88259

Wong, C. G., Bottiglieri, T., and Snead, O. C. III. (2003). GABA, gammahydroxybutyric acid, and neurological disease. Ann. Neurol. 54(Suppl. 6), S3-S12. doi: 10.1002/ana.10696

Wu, Y., Wang, W., Diez-Sampedro, A., and Richerson, G. B. (2007). Nonvesicular inhibitory neurotransmission via reversal of the GABA transporter GAT-1. Neuron 56, 851-865. doi: 10.1016/j.neuron.2007.10.021

Xie, R., and Manis, P. B. (2013). Target-specific IPSC kinetics promote temporal processing in auditory parallel pathways. J. Neurosci. 33, 1598-1614. doi: 10.1523/JNEUROSCI.2541-12.2013

Conflict of Interest Statement: The authors declare that the research was conducted in the absence of any commercial or financial relationships that could be construed as a potential conflict of interest.

Received: 10 February 2014; accepted: 28 April 2014; published online: 15 May 2014. Citation: Christensen RK, Petersen AV, Schmitt N and Perrier J-F (2014) Fast detection of extrasynaptic GABA with a whole-cell sniffer. Front. Cell. Neurosci. 8:133. doi: 10.3389/fncel.2014.00133

This article was submitted to the journal Frontiers in Cellular Neuroscience. Copyright (C) 2014 Christensen, Petersen, Schmitt and Perrier. This is an open-access article distributed under the terms of the Creative Commons Attribution License (CC BY). The use, distribution or reproduction in other forums is permitted, provided the original author(s) or licensor are credited and that the original publication in this journal is cited, in accordance with accepted academic practice. No use, distribution or reproduction is permitted which does not comply with these terms. 